\title{
Variable Dielectrics in the Calcium Magnesium Titanate System Characterized with Scanning Microwave Microscopy
}

\author{
Zachary N. Wing ${ }^{\star \dagger}$ and John W. Halloran** \\ Department of Materials Science Engineering, University of Michigan, Ann Arbor, Michigan, 48109
}

Qinxin Zhang* and Paul J. McGinn*

Department of Chemical and Biomolecular Engineering, University of Notre Dame, Notre Dame, Indiana 46556

\begin{abstract}
Near-field scanning microwave microscopy (SMM) is used to observe the fine-scale dielectric phenomena. The purpose of the present study is to apply the SMM to examine the dielectrics in the multiphase CT-MT- $M_{2} \mathrm{~T}$ system and study the dielectric relative permittivity $\varepsilon_{\mathrm{r}}^{\prime}$ distribution. SMM clearly resolves the three-phase distribution and is in agreement with chemical analysis.
\end{abstract}

\section{Introduction}

$\mathrm{T}$ $\mathrm{HE} \mathrm{CaTiO}_{3}-\mathrm{MgTiO}_{3}-\mathrm{Mg}_{2} \mathrm{TiO}_{4}\left(\mathrm{CT}-\mathrm{MT}-\mathrm{M}_{2} \mathrm{~T}\right)$ system consists of three thermo-chemically compatible phases, each with a different value of relative permittivity $\left(\varepsilon_{\mathrm{r}}^{\prime}\right)$. Thus, a range of values for relative permittivity are possible and can be obtained by varying the relative concentration of each phase. The macroscopic $\varepsilon_{\mathrm{r}}^{\prime}$ results from a mixing of the individual phases. Local variations in $\varepsilon_{\mathrm{r}}^{\prime}$ are associated with local variation of phase composition. We produce monolithic materials with variations in phase compositions, and seek to measure the permittivity variation.

Dielectrics are important for electro-magnetic device miniaturization. In particular, advanced UHF antenna designs rely on dielectric loading in the form of substrates or superstrates. ${ }^{1}$ Spatial variation of the permittivity $\left(\varepsilon_{\mathrm{r}}^{\prime}\right)$, or "dielectric texturization," can be used to optimize antenna performance. ${ }^{2}$ Monolithic materials are desirable to maintain device integrity, so it is preferable to achieve the permittivity variations in a monolithic co-fired ceramic substrate.

Calcium magnesium titanates are a technologically important family of dielectrics of interest for microwave applications. They consist of the high $\varepsilon_{\mathrm{r}}^{\prime} \mathrm{CaTiO}_{3}$ and low $\varepsilon_{\mathrm{r}}^{\prime} \mathrm{Mg}$-titanates. Microwave dielectrics based on $\mathrm{MgTiO}_{3}$ typically have $\mathrm{CaTiO}_{3}$ mixed in to balance out their negative temperature coefficient $\left(\tau_{\mathrm{f}}\right)^{3}$ Owing to temperature stability issues, the composition of $\mathrm{Mg}_{95} \mathrm{Ca}_{5}$ is well studied due to its zero $\tau_{\mathrm{f}}$. Compositions within the $\mathrm{CaTiO}_{3}-\mathrm{MgTiO}_{3}-\mathrm{Mg}_{2} \mathrm{TiO}_{4}\left(\mathrm{CT}-\mathrm{MT}-\mathrm{M}_{2} \mathrm{~T}\right)$ phase system are of interest due to the wide $\varepsilon_{\mathrm{r}}^{\prime}$ range available and moderate to high $Q$. Variable compositions within this region exhibit co-fire compatibility and allow for monolithic texturization in $\varepsilon_{\mathrm{r}}^{\prime}$.

$\mathrm{CaTiO}_{3}$ (perovskite) is a high $\varepsilon_{\mathrm{r}}^{\prime}$ material $\left(\varepsilon_{\mathrm{r}}^{\prime}=170\right)$, high $\tau_{\mathrm{f}}$ $\left(+800 \mathrm{ppm} /{ }^{\circ} \mathrm{C}\right)$, and moderate $Q(\sim 1800-3000) .{ }^{4} \mathrm{MgTiO}_{3}$ (giekielite) has a low $\varepsilon_{\mathrm{r}_{3}}^{\prime}(17)$, a negative $\tau_{\mathrm{f}}\left(-45 \mathrm{ppm} /{ }^{\circ} \mathrm{C}\right)$, and a high $Q(7000-20800){ }^{3} \mathrm{Mg}_{2} \mathrm{TiO}_{4}$ (qandilite) also has a low $\varepsilon_{\mathrm{r}}^{\prime}$ (12), a negative $\tau_{\mathrm{f}}$, and a low $Q(670){ }^{5}$

D. Johnson - contributing editor

Manuscript No. 20992. Received September 13, 2005; approved January 16, 2006 ${ }^{*}$ Member, American Ceramic Society.

*^ Fellow, American Ceramic Society.

Author to whom correspondence should be addressed. e-mail: wingzach@umich.edu
Recently, scanning microwave microscopy (SMM) has been demonstrated to be an effective tool for analyzing the dielectric properties of bulk samples at the microstructural level. This has been demonstrated in $\mathrm{LaAlO}_{3}, \mathrm{TiO}_{2}$ single crystals, and bulk yttria-stabilized zirconia (YSZ). ${ }^{6}$ The nondestructive mapping technique of near-field SMM can allow characterization of the effects of inhomogeneities and defects in crystals, thin films, and bulk ceramics on the local dielectric behavior. ${ }^{6}$ Two recent reviews describe the development of SMM. ${ }^{7-8}$ A schematic diagram of the SMM applied in this study is described elsewhere. ${ }^{6}$ The SMM is designed to shield off the far-field propagating electromagnetic wave and utilize evanescent microwaves generated at the end of a tungsten tip. By moving the tip/cavity assembly closely over a ceramic object, the interaction between the evanescent field and the object can be recorded to map changes in the cavity resonant frequency $f_{r}$ and quality factor $Q$ as a function of position and generate surface SMM images. The effect of the sample dielectric properties on the cavity resonant frequency can be summarized as follows: when the sample $\varepsilon_{\mathrm{r}}^{\prime}$ is higher, the leakage of the evanescent microwave from the tip is higher, and therefore the cavity resonant frequency is lower. Hence, a lower cavity resonant frequency indicates a higher sample $\varepsilon_{\mathrm{r}}^{\prime}$. The goal of this paper is to characterize variable $\left(\varepsilon_{\mathrm{r}}^{\prime}\right)$ dielectrics within the CMT system presented using SMM and to verify the results with traditional chemical methods.

\section{Experimental Procedure}

\section{(1) Materials and Processing}

Four dielectric powders were selected with different $\varepsilon_{\mathrm{r}}^{\prime}$ 's. All powders are commercially available calcium magnesium titanates (Trans-Tech, Adamstown, MD). These powders are spray dried so that they are intentionally agglomerated into $100 \mu \mathrm{m}$ spherical granules to improve dry powder flow and compaction. Dielectrics were selected by their specific $\varepsilon_{\mathrm{r}}^{\prime}$ values of $20,30,40$, and 115. Table I lists the manufacturer specifications of these dielectrics.

Three samples were fabricated. The first sample consisted of a $50 \mathrm{vol} \%$ mixture of the $\varepsilon_{\mathrm{r}}^{\prime}=20$ and $\varepsilon_{\mathrm{r}}^{\prime}=40$ precursor powders. The second sample was a $50 \mathrm{vol} \%$ mixture between the $\varepsilon_{\mathrm{r}}^{\prime}=20$ and $\varepsilon_{\mathrm{r}}^{\prime}=115$ powders. Mixtures were obtained via wet mixing in isopropyl alcohol for $15 \mathrm{~min}$. Powders were dried at $65^{\circ} \mathrm{C}$ until all alcohol was removed. Powders were pressed inside a cylin-

Table I. Properties of Commercial CMTs

\begin{tabular}{lccc}
\hline Powder & $\varepsilon_{\mathrm{r}}^{\prime}>(6 \mathrm{GHz})$ & Loss tangent & Density $(\mathrm{g} / \mathrm{cc})$ \\
\hline CMT 20 & 20 & $<0.0015$ & 3.00 \\
CMT 30 & 30 & $<0.0015$ & 3.59 \\
CMT 40 & 40 & $<0.0015$ & 3.62 \\
CMT 115 & 115 & $<0.0015$ & 3.80 \\
\hline
\end{tabular}

CMT, calcium magnesium titanate. 


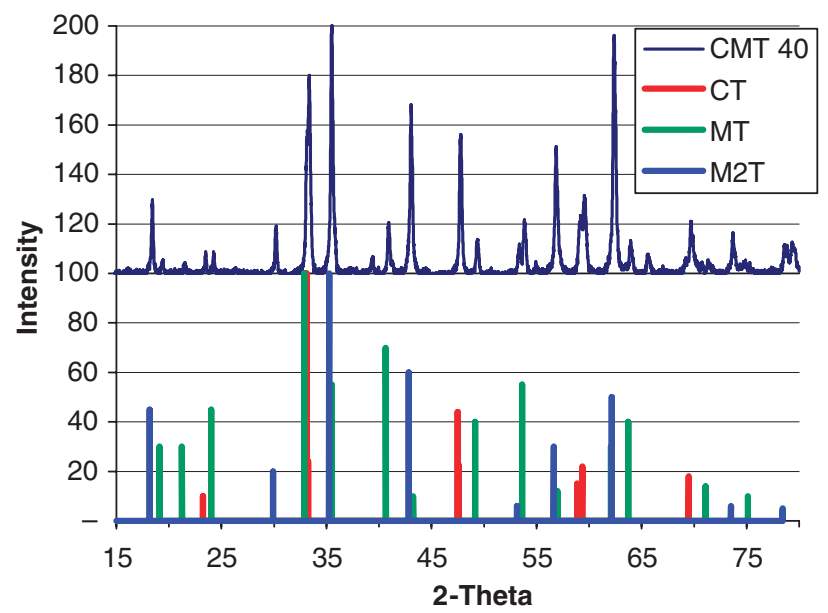

Fig. 1. X-ray powder diffraction of $\varepsilon_{\mathrm{r}}^{\prime}=40$ calcium magnesium titanate.

Table II. Relative Phase Composition of Variable $\varepsilon_{\mathrm{r}}^{\prime}$ CMT

\begin{tabular}{lcccr}
\hline & CMT 20 & CMT 30 & CMT 40 & CMT 115 \\
\hline $\mathrm{CaTiO}_{3}$ & $13.3 \%$ & $23 \%$ & $37 \%$ & $81.8 \%$ \\
$\mathrm{MgTiO}_{3}$ & $1.2 \%$ & $7.2 \%$ & $5 \%$ & $8.0 \%$ \\
$\mathrm{Mg}_{2} \mathrm{TiO}_{4}$ & $85.5 \%$ & $69.8 \%$ & $58 \%$ & $10.2 \%$ \\
\hline
\end{tabular}

CMT, calcium magnesium titanate.

drical steel die with a diameter of $12.79 \mathrm{~mm}$ at a pressure of 75 $\mathrm{MPa}$. The third sample involved co-firing the $\varepsilon_{\mathrm{r}}^{\prime}=30$ and the $\varepsilon_{\mathrm{r}}^{\prime}=40$ powder together to create an interface. A special fixture was developed to separate the powders within a $47 \mathrm{~mm} \times 44 \mathrm{~mm}$ rectangular steel die. First, the unsupported side of the die was filled with the $\varepsilon_{\mathrm{r}}^{\prime}=30$ powder. Next, the $\varepsilon_{\mathrm{r}}^{\prime}=40$ powder was added to the supported side until one half the divider height. The support was carefully removed and the remaining powder was added to the $\varepsilon_{\mathrm{r}}^{\prime}=40$ side. Finally, the divider was slowly removed and the powder was pressed at $75 \mathrm{MPa}$. All samples were sintered in air at $1360^{\circ} \mathrm{C}$ for $4 \mathrm{~h}$ using a heating and cooling rate of $10^{\circ} \mathrm{C} / \mathrm{min}$.

\section{(2) Characterization}

The phase composition was analyzed using X-ray diffraction of powder samples (Rigaku Miniflex, The Woodlands, TX). Microstructure and elemental analysis via energy-dispersive spectroscopy (EDS) was performed on sintered samples (Phi-

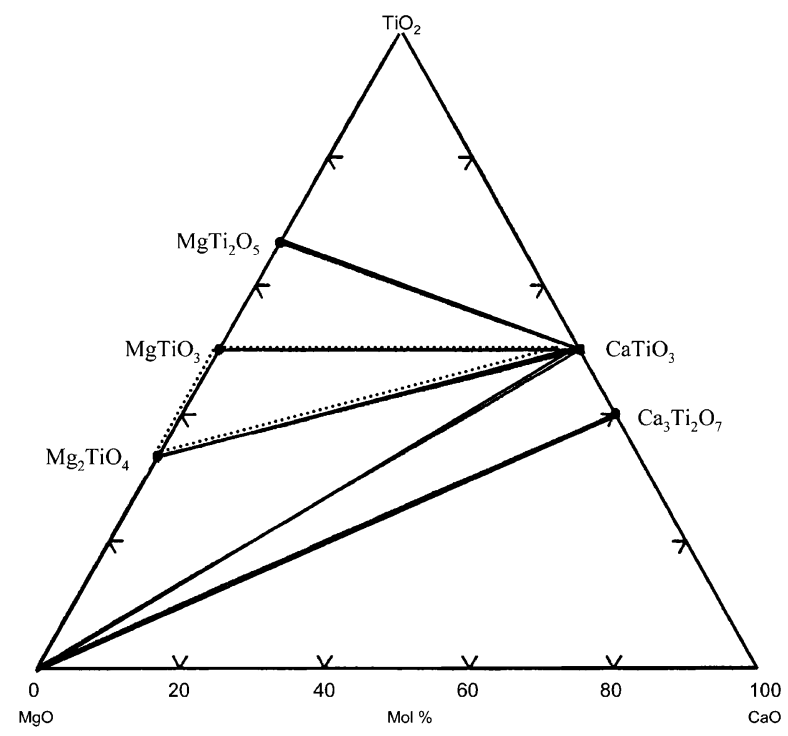

Fig. 2. Phase diagram for $\mathrm{CaO}-\mathrm{MgO}-\mathrm{TiO}_{2}{ }^{9}$

lips XL-30, Philips Electronics N.V., Eindhoven, the Netherlands, and EDAX Phoenix XEDS, AMETEK, Inc., Mahwah, NJ). Samples were also imaged using backscattered electron SEM (BSE-SEM, Oxford Instruments, Eynsham, UK). A Vicker's micro hardness indenter was used to mark areas of interest (Buehler Micromet II, Lake Bluff, IL) using a $1 \mathrm{~kg}$ load for $10 \mathrm{~s}$. Finally, SMM was performed to analyze the dielectric distribution (EMP2001, Ariel Technology Inc., Fremont, CA). The calibration curve for this system has been presented previously by Zhang and McGinn. ${ }^{6}$ The current SMM system had a loss tangent $\sim 10^{-3}(Q \sim 1000)$; thus, extraction of variations in material $Q$ was limited to samples with a $Q<1000$ and is not reported here. All samples were polished down to $1 \mu \mathrm{m}$. This was done to minimize surface roughness effects and roughness uncertainties. All scans were performed with the probe tip in contact with the surface ("soft contact" mode).

X-ray diffraction was performed to verify the phase composition and identity any impurities. Three phases were identified: $\mathrm{CaTiO}_{3}, \mathrm{MgTiO}_{3}$, and $\mathrm{Mg}_{2} \mathrm{TiO}_{4}$. Figure 1 shows the experimental diffraction pattern for the $\varepsilon_{\mathrm{r}}^{\prime}=40$ composition compared with the JCPDF for the three phases (PDF\#42-0423, PDF\#06-0494, PDF\#25-1157).

Table II shows the relative phase composition of the dielectrics. Relative phase analysis was calculated using Jade 3.1 semiquantitative analysis. $\mathrm{MgTiO}_{3}$ was the most minor phase in all compositions. $\mathrm{Mg}_{2} \mathrm{TiO}_{4}$ was the bulk phase, except for the
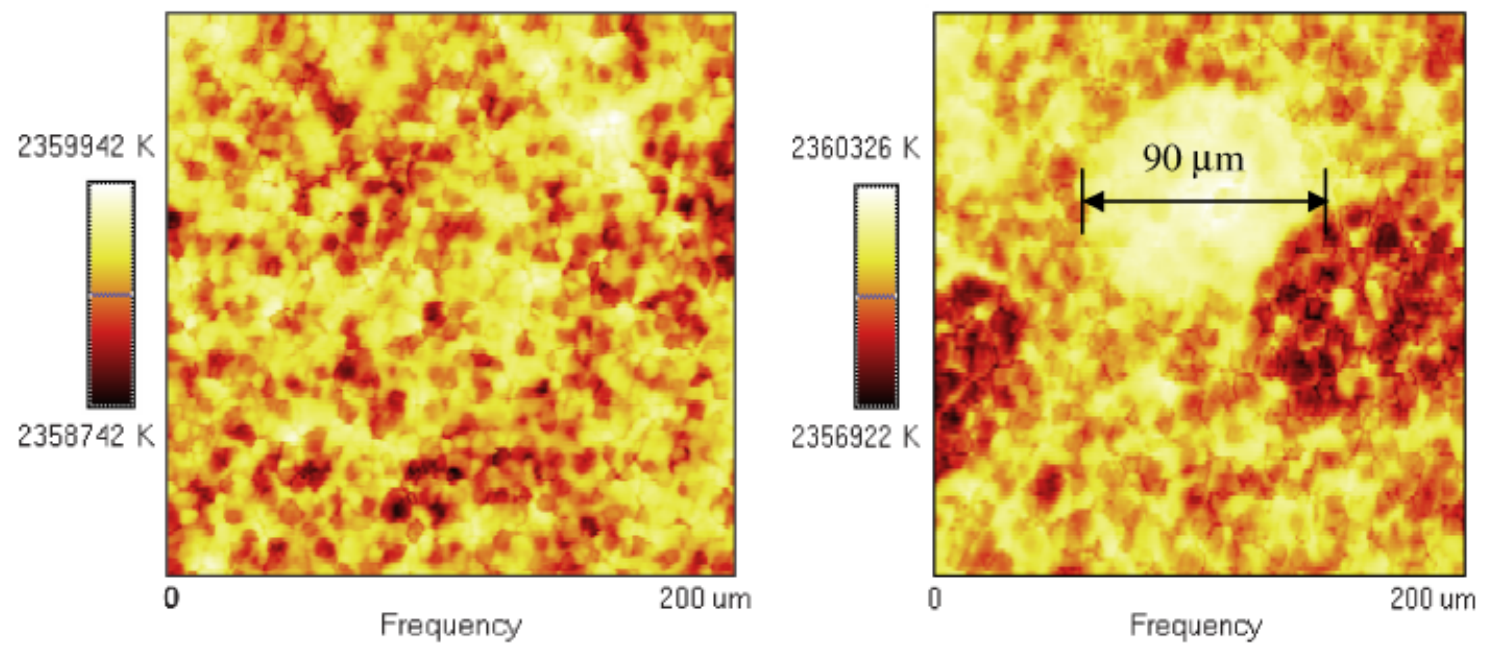

Fig. 3. Scanning microwave microscopy mapping of mixtures (left) $\varepsilon_{\mathrm{r}}^{\prime}=20-40$; (right) $\varepsilon_{\mathrm{r}}^{\prime}=20-115$. 

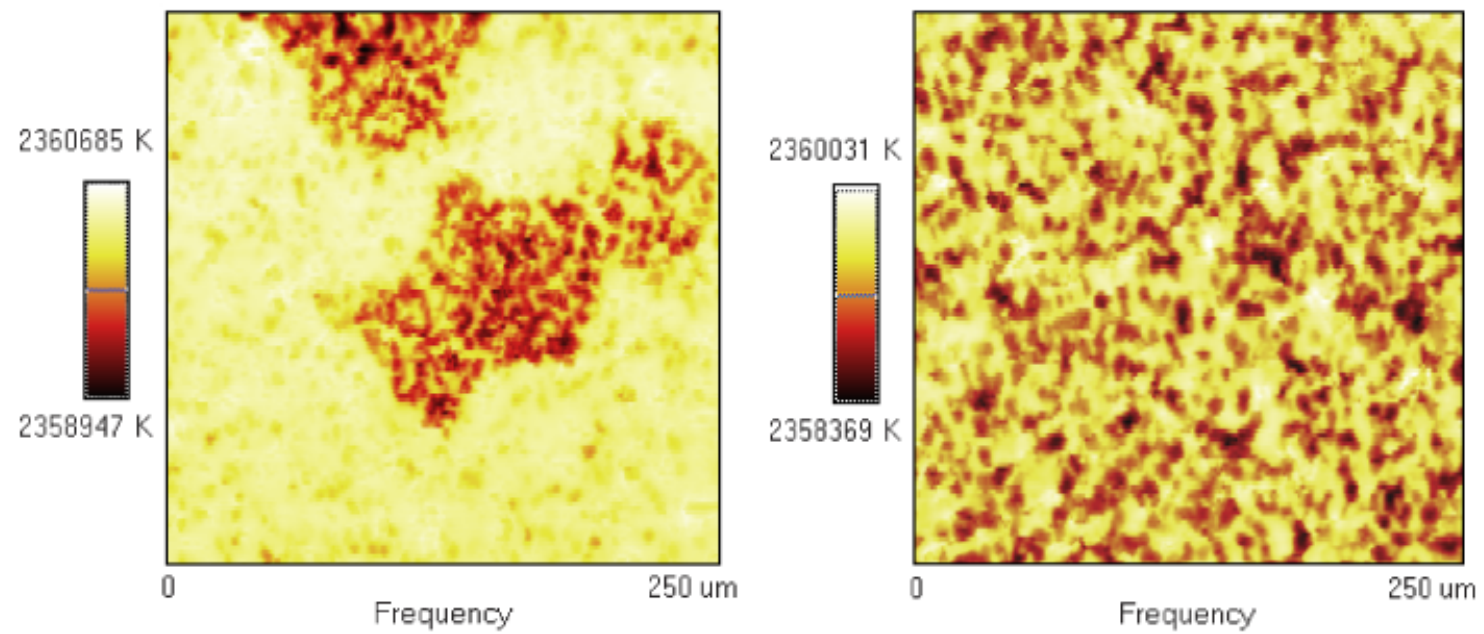

Fig. 4. (Left) scanning microwave microscopy (SMM) mapping of the $\varepsilon_{\mathrm{r}}^{\prime}=30$ side in which large clusters exist; (right) $\mathrm{SMM}$ mapping of the $\varepsilon_{\mathrm{r}}^{\prime}=40$ side showing a homogeneous $\varepsilon_{\mathrm{r}}^{\prime}$ distribution.

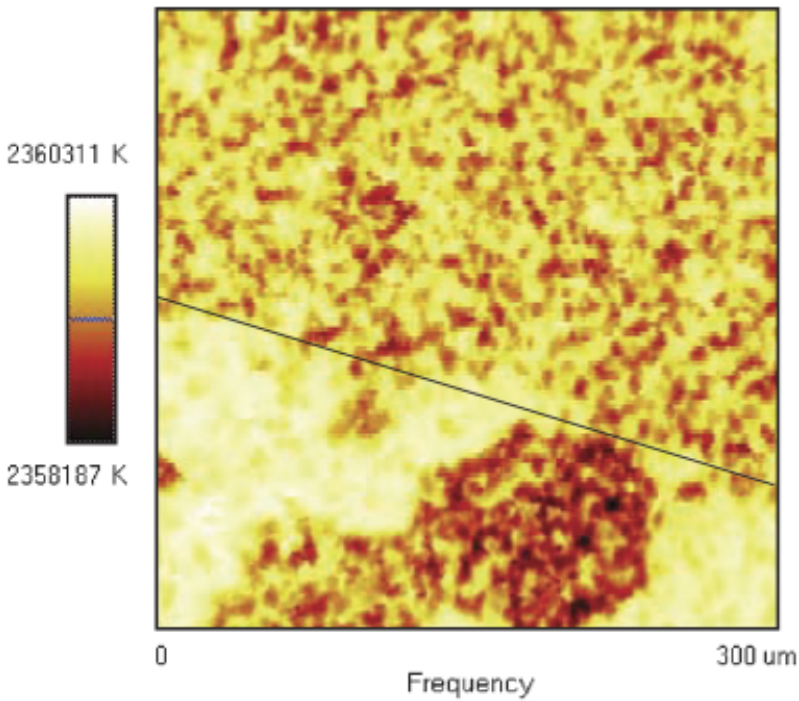

Fig. 5. Scanning microwave microscopy mapping of the interface showing homogeneous and cluster regions.

$\varepsilon_{\mathrm{r}}^{\prime}=115$ powder, which had a higher amount of $\mathrm{CaTiO}_{3}$ as can be expected. These three phases co-existed within a discrete region of the $\mathrm{CaO}-\mathrm{MgO}-\mathrm{TiO}_{2}$ phase diagram shown in Fig. 2.

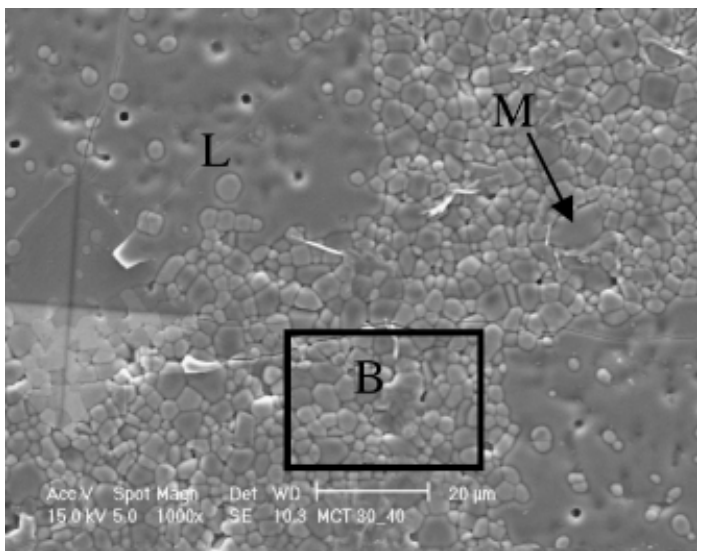

\section{Results and Discussion}

\section{(1) SMM Imaging of Mixtures}

Traditional microwave characterization methods are capable of analyzing dielectric mixtures with high levels of precision. These include resonance or perturbation techniques. ${ }^{10-11}$ These measurements are critical for integration of materials into devices, but they essentially yield the effective average properties of the mixture.

SMM imaging was performed on a polished $\varepsilon_{\mathrm{r}}^{\prime}=20-40$ sample. Figure 3 shows the resonant frequency mapping of the surface at a $200 \mu \mathrm{m}$ length scale. Three distinct colors are shown, indicating the presence of three dielectric phases. In the resonant frequency mapping, they appear as red, yellow, and white. The colored bar scale indicates the resonant frequency (where the " $K$ " indicates $\times 1000$ ). The three phases appeared to be homogeneously distributed. The presence of three phases agrees well with the X-ray diffraction findings.

Similar results were obtained in the $\varepsilon_{\mathrm{r}}^{\prime}=20-115$ mixture. However, there existed regions of inhomogeneity evidenced by clusters of high and low $\varepsilon_{\mathrm{r}}^{\prime}$ regions. Figure 3 shows a $200 \mu \mathrm{m}$ field of view. The cluster shown is approximately $90 \mu \mathrm{m}$ in diameter. Regions of large-scale inhomogeneity were not observed in the $\varepsilon_{\mathrm{r}}^{\prime}=20-40$ mixture.

\section{(2) SMM Imaging of 30-40 Interface}

Individual sides of the interface were examined independently. Figure 4 (left) shows the presence of large-scale regions of low $\varepsilon_{\mathrm{r}}^{\prime}=20-40$ and high $\varepsilon_{\mathrm{r}}^{\prime}$ on the $\varepsilon_{\mathrm{r}}^{\prime}=30$ side. The $\varepsilon_{\mathrm{r}}^{\prime}=40$ side

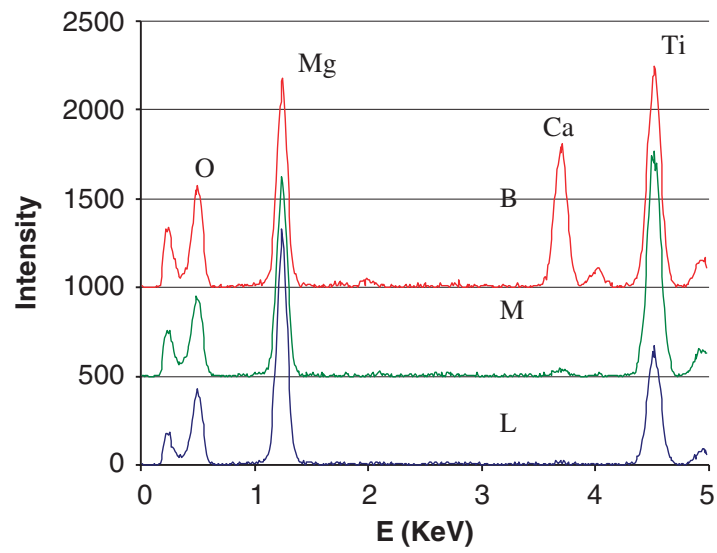

Fig. 6. (Left) energy-dispersive spectroscopy (EDS) region of $\varepsilon_{\mathrm{r}}^{\prime}=30$ interface sample (very large grains present in the upper left and lower right); (right) EDS spectra from the three labeled regions. 
Table III. Theoretical Element Weight Fractions for Each Phase

\begin{tabular}{lrrrr}
\hline Phase & \multicolumn{1}{c}{$\mathrm{Ca}$} & $\mathrm{Mg}$ & $\mathrm{Ti}$ & $\mathrm{O}$ \\
\hline $\mathrm{CaTiO}_{3}$ & 29.5 & 0.0 & 35.2 & 35.3 \\
$\mathrm{MgTiO}_{3}$ & 0.0 & 20.2 & 39.8 & 39.9 \\
$\mathrm{Mg}_{2} \mathrm{TiO}_{4}$ & 0.0 & 30.3 & 29.8 & 39.9 \\
\hline
\end{tabular}

Table IV. Element Weight Fractions Based on EDS

\begin{tabular}{lrccc}
\hline Region/Area & $\mathrm{Ca}$ & $\mathrm{Mg}$ & $\mathrm{Ti}$ & $\mathrm{O}$ \\
\hline$\varepsilon_{r}^{\prime}=$ 30(JADE XRD) & 6.8 & 22.6 & 31.8 & 38.8 \\
$\mathrm{~B}$ & 12.0 & 20.0 & 26.5 & 41.5 \\
$\mathrm{M}$ & 0.8 & 23.6 & 34.7 & 40.9 \\
$\mathrm{~L}$ & 0.3 & 34.4 & 24.6 & 40.7 \\
\hline \multicolumn{2}{c}{ EDS, energy-dispersive spectroscopy. }
\end{tabular}

EDS, energy-dispersive spectroscopy.

(Fig. 4 right) shows a homogeneous distribution of three phases, in agreement with the homogeneous mixture imaged earlier.

SMM imaging of the $\varepsilon_{\mathrm{r}}^{\prime}=30-40$ interface was enabled due to the differences in phase distributions between the two regions. Figure 5 shows an image of the distinct interface region with large clusters $(\sim 200 \mu \mathrm{m})$ bordering a more homogenous region.

The lowest frequency RED phase corresponds to the high $\varepsilon_{\mathrm{r}}^{\prime}$ $\mathrm{CaTiO}_{3}$ phase. The white and yellow colors indicate the low $\varepsilon_{\mathrm{r}}^{\prime}$ phases that correspond to the $\mathrm{MgTiO}_{3}$ and $\mathrm{Mg}_{2} \mathrm{TiO}_{4}$ phases, respectively. XRD data showed the $\mathrm{M}_{2} \mathrm{~T}$ phase to be the most abundant, and the MT phase to be the least abundant. Thus, the $\mathrm{M}_{2} \mathrm{~T}$ phase corresponds to the yellow shade and the MT phase corresponds to the white one. The clustering and formation of inhomogeneous regions are likely due to commercial powder processing. The spray-drying process produces $100-200 \mu \mathrm{m}$ agglomerates. In addition, the relative phase ratio can be adjusted by varying the powder formulation before spray drying (producing homogeneity) or after spray drying (producing clusters).

\section{(3) EDS Analysis of 30-40 Interface}

A series of Vicker's micro indents were used to label the interface region ( $1000 \mathrm{~g}$ load for $10 \mathrm{~s}$ ). A readily identifiable region of interest was selected on the $\varepsilon_{\mathrm{r}}^{\prime}=30$ material. This area consisted of a fine-grained region located between two large grains. An EDS analysis revealed a strong elemental difference between the regions. Large-scale inhomogeneities occurred on the scale of $(100-200 \mu \mathrm{m})$. Figure 6 shows the region studied with EDS and SMM. The large grain (L) in Fig. 6 shows very little calcium and is high in $\mathrm{Mg}-\mathrm{Ti}-\mathrm{O}$. The fine-grained region (boxed) shows a

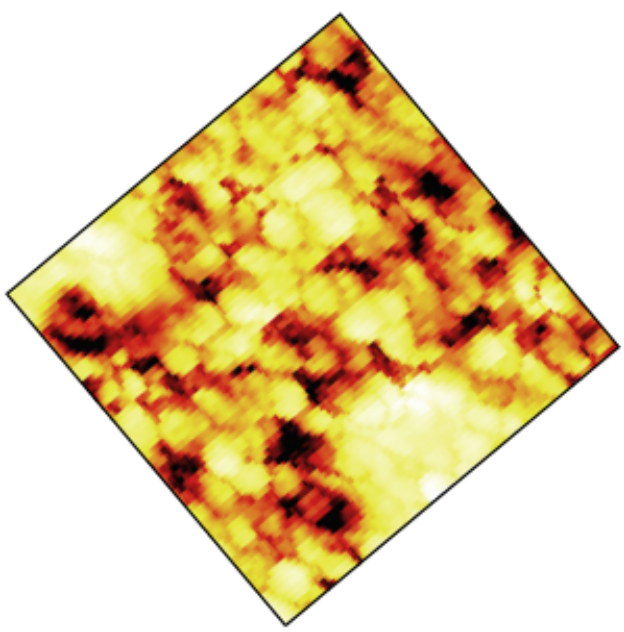

Fig. 8. Scanning microwave microscopy image of the energy-dispersive spectroscopy region $(100 \mu \mathrm{m})$.

distinctly higher Ca presence in addition to $\mathrm{Mg}$ and $\mathrm{Ti}$. A $10 \mu \mathrm{m}$ grain (M) was located in the fine-grained region and also showed minimal Ca composition.

Table III shows the theoretical element weight fractions for each phase. Elemental weight fractions of $\mathrm{Mg}$ and $\mathrm{Ti}$ were determined for region $\mathrm{L}$ to be $34.4 \mathrm{wt} \%$ and $24.6 \mathrm{wt} \%$, respectively. This agrees best with the $\mathrm{Mg}-\mathrm{Ti}$ theoretical fractions for the $\mathrm{Mg}_{2} \mathrm{TiO}_{4}$ composition $30.3 \mathrm{wt} \%$ and $29.8 \mathrm{wt} \%$.

The low Ca grain labeled "M" showed Mg-Ti weight fractions of $23.6 \mathrm{wt} \%$ and $34.7 \mathrm{wt} \%$, respectively, in Table IV. This agrees best with the $\mathrm{MgTiO}_{3}$ phase, whose $\mathrm{Mg}$-Ti fractions were $20.2 \mathrm{wt} \%$ and $34.7 \mathrm{wt} \%$. Finally, the fine-grained region (B) shows the presence of $\mathrm{Ca}$ in addition to $\mathrm{Mg}$ and $\mathrm{Ti}$. Elemental fractions for this region showed $12.0 \mathrm{wt} \% \mathrm{Ca}, 20.0 \mathrm{wt} \% \mathrm{Mg}$, and $26.5 \mathrm{wt} \%$ Ti. Thus, the high $\varepsilon_{\mathrm{r}}^{\prime} \mathrm{CaTiO}_{3}$ phase existed in a low overall fraction and in the fine-grained regions. For the low $\varepsilon_{\mathrm{r}}^{\prime}$ phases, the $\mathrm{Mg}_{2} \mathrm{TiO}_{4}$ phase occupied the large grains and $\mathrm{MgTiO}_{3}$ existed in the fine-grained region.

\section{(4) SMM Analysis of 30-40 Interface}

SMM imaging was used to analyze the EDS region discussed above. Figure 7 shows the SMM large field of view.

The EDS region can be identified using the row of micro indents (detected as white squares in the SMM image) and the large low $\varepsilon_{\mathrm{r}}^{\prime}$ yellow regions in the upper right image. The arrows indicate the same indented location in the SMM and SEM
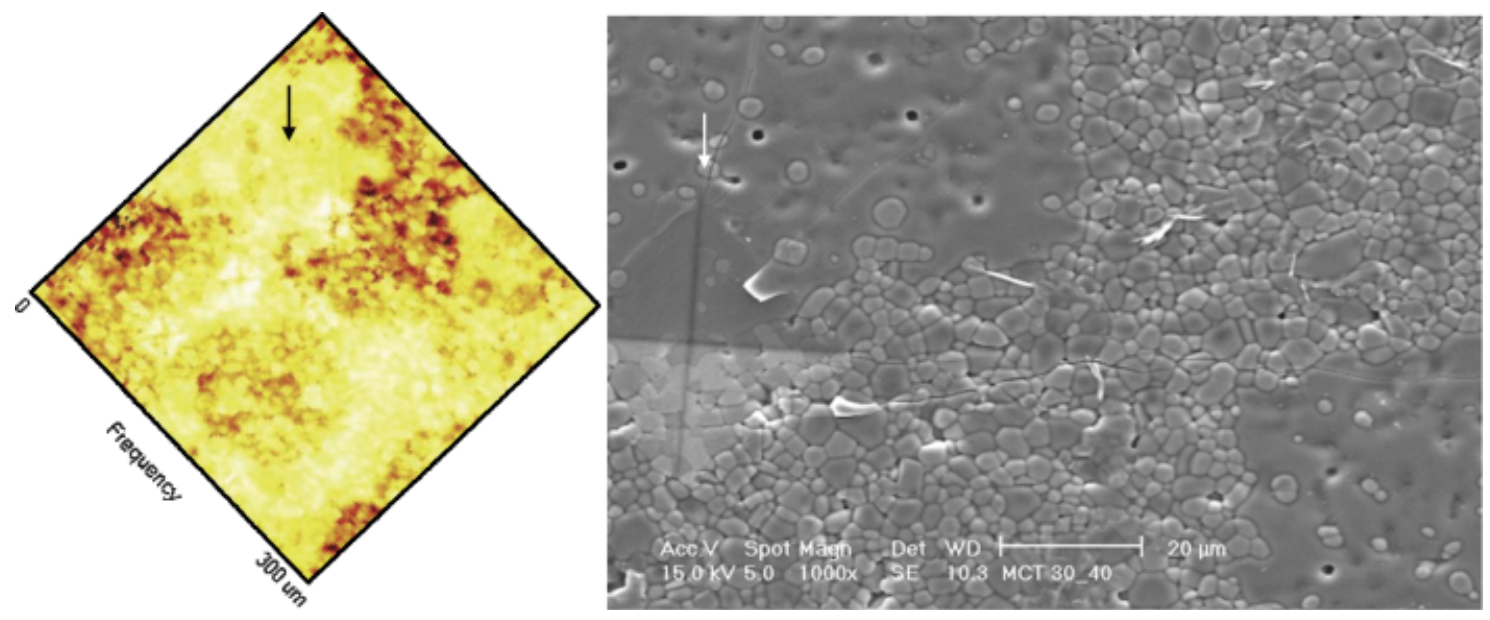

Fig. 7. (Left) scanning microwave microscopy (SMM) image of the energy-dispersive spectroscopy region. Micro indents are visible as white squares in SMM. The right indent (black arrow in the left figure above) corresponds to the one shown in the SEM image (white arrow in the right figure above). 

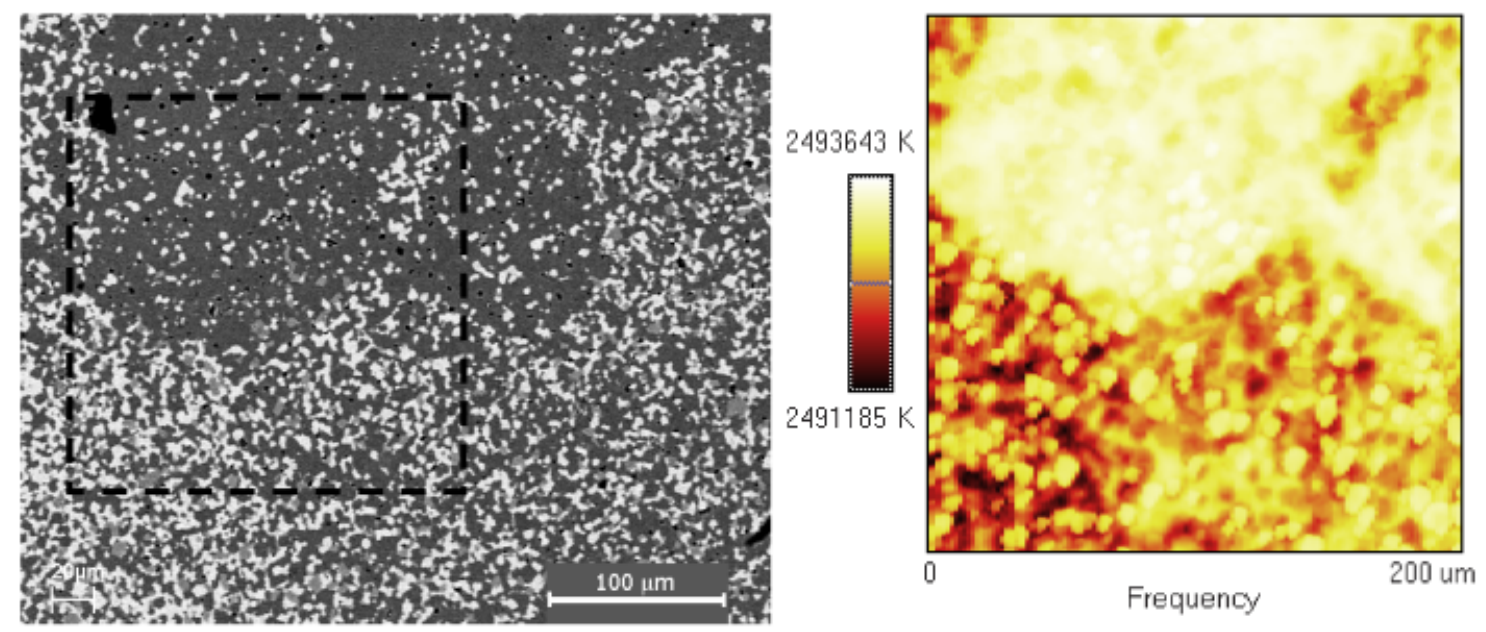

Fig. 9. (Left) backscattered electron SEM image of $\varepsilon_{\mathrm{r}}^{\prime}=3040$ interface; (right) scanning microwave microscopy image of the boxed region.

images. Figure 8 shows a smaller field of view, which corresponds to the area shown in the SEM image of Fig. 7. The large grains clearly indicate islands of a homogeneous low $\varepsilon_{\mathrm{r}}^{\prime}$ dielectric. This is in agreement with the EDS findings of $\mathrm{Mg}_{2} \mathrm{TiO}_{4}$.

SMM results of the fine-grained area between the large $\mathrm{M}_{2} \mathrm{~T}$ grains indicated a mixture of high-contrast dielectrics. A high $\varepsilon_{\mathrm{r}}^{\prime}$ (red) is presented in a mixture of two low $\varepsilon_{\mathrm{r}}^{\prime}$ dielectrics. EDS findings were similar, indicating significant weight fractions of $\mathrm{Ca}$ and $\mathrm{Mg}$.

\section{(5) BSE Comparison}

A second $\varepsilon_{\mathrm{r}}^{\prime}=30-40$ polished interface sample was investigated by BSE-SEM and contact mode SMM in order to compare different phases' permittivity behavior. Figure 10 shows the BSE-SEM image at the polished interface of $\varepsilon_{\mathrm{r}}^{\prime}=30$ and $\varepsilon_{\mathrm{r}}^{\prime}=$ 40 with the corresponding SMM image. The $\mathrm{CaTiO}_{3}$ phase appears as a light-colored phase in the BSE-SEM image, the dark color regions represent the $\mathrm{M}_{2} \mathrm{~T}$ phase, while the gray regions represent the MT phase. The identity of these three phases was confirmed by EDS analysis.

The corresponding SMM image of the boxed region in Fig. 9 (left) is shown in Fig. 9 (right). The resonant frequency image indicates that the CT phase has the lowest resonant frequency (highest $\varepsilon_{\mathrm{r}}^{\prime}$ ), MT has the highest resonant frequency (lowest $\varepsilon_{\mathrm{r}}^{\prime}$ ), while the $\mathrm{M}_{2} \mathrm{~T}$ continuous phase has a slightly lower resonant frequency than the MT phase. A higher magnification SMM image inside the $\mathrm{M}_{2} \mathrm{~T}$ cluster area is shown in Fig. 10. The continuous $\mathrm{M}_{2} \mathrm{~T}$ phase appears as a light yellow color, dark grains

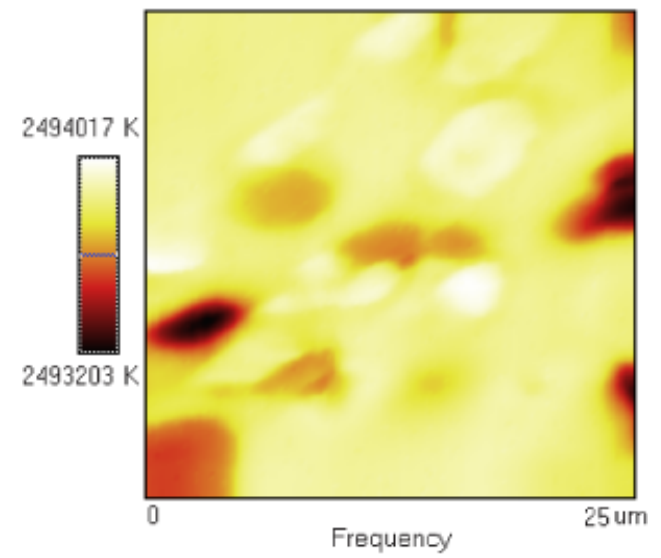

Fig. 10. High-magnification scanning microwave microscopy image inside the $\mathrm{M}_{2} \mathrm{~T}$ cluster. represent the CT phase, while the light (white) phase represents MT. This reveals the relative ranking of dielectric constants of these three phases: $\varepsilon_{\mathrm{rCT}}^{\prime}>\varepsilon_{\mathrm{rM}_{2} \mathrm{~T}}^{\prime}>\varepsilon_{\mathrm{rMT}}^{\prime}$.

The SMM collects the signal from a region larger than the tip. Hence, the resolution depends on the tip geometry. The size of the tip used in Figs. 9 and 10 was about $10 \mu \mathrm{m}$, whereas the particles of CT and MT were around $1-5 \mu \mathrm{m}$ in size. Thus, the SMM images had blurred particle boundaries instead of sharp boundaries like in the BSE-SEM images.

\section{Conclusion}

Calcium magnesium titanates with variable composition and variable dielectric properties were analyzed using SMM. SMM clearly distinguished $\mathrm{CT}, \mathrm{MT}$, and $\mathrm{M}_{2} \mathrm{~T}$ by contrast in $\varepsilon_{\mathrm{r}}^{\prime}$ with a resolution of $5 \mu \mathrm{m}$. Interfaces between macroscopic regions of $\varepsilon_{\mathrm{r}}^{\prime}=30$ and $\varepsilon_{\mathrm{r}}^{\prime}=40$ were clearly resolved. Individual features imaged both by SMM and SEM/EDS/BSE confirmed the phase distribution of $\mathrm{CaTiO}_{3}, \mathrm{MgTiO}_{3}$, and $\mathrm{Mg}_{2} \mathrm{TiO}_{4}$.

\section{References}

${ }^{1}$ G. Kiziltas, N. Kikuchi, J. L. Volakis, and J. W. Halloran, "Topology Optimization of Dielectric Substrates for Filters and Antennas Using SIMP," Arch. Comput. Methods Eng., 11 [4] 355-88 (2004).

${ }^{2}$ G. Kiziltas, D. Psychoudakis, J. L. Volakis, and N. Kikuchi, "Topology Design Optimization of Dielectric Substrates for Bandwidth Improvement of a Patch Antenna," IEEE Trans. Antennas. Propag., 51 [10, part1] 2732-43 (2003).

${ }^{3}$ V. M. Ferreira, F. Azough, R. Freer, and J. L. Baptista, "The Effect of Cr and $\mathrm{La}$ on $\mathrm{MgTiO}_{3}$ and $\mathrm{MgTiO}_{3}-\mathrm{CaTiO}_{3}$ Microwave Dielectric Ceramics," J. Mater. Res., 12, 3293-9 (1997).

${ }^{4}$ J. Zeng, H. Wang, S. Shang, Z. Wang, and C. Lin, "Preparation of Textured $\mathrm{Mg}_{2} \mathrm{TiO}_{4}$ Thin Films on Si Substrate by Atmospheric Pressure Metallorganic Chemical Vapour Deposition," J. Mater. Sci. Mater. Electron., 8, 159-62 (1997).

${ }^{5} \mathrm{H}$. Haefie, H. P. Lang, R. Sum, H. J. Guntherodt, L. Berthold, and D. Hesse, " $\mathrm{Mg}_{2} \mathrm{Ti}_{4}$ As a Novel Substrate for High-Temperature Superconducting Thin Films," Appl. Phys. Lett., 61 [19] 9 (1992).

${ }^{6} \mathrm{Q}$. Zhang and P. J. McGinn, "Imaging of Oxide Dielectrics by Near-Field Microwave Microscopy," J. Eur. Ceram. Soc., 25 [4] 407-16 (2005).

${ }^{7}$ X. D. Xiang and C. Gao, "Quantitative Complex Electrical Impedance Microscopy by Scanning Evanescent Microwave Microscope," Mater. Charact., 48 [2/3] 117-25 (2002).

${ }^{8}$ B.T Rosner and D. W. Van Der Weide, "High-Frequency Near-Field Microscopy," Rev. Sci. Instrum., 73 [7] 2505-25 (2002).

${ }^{9}$ L. W. Coughanour, R. S. Roth, S. Marzullo, and F. E. Sennett, "Solid State Reactions and Dielectric Properties in the System Magnesia-Lime-Tin-OxideTitania," J. Res. Nat. Bur. Stand. (U. S.), 54 [3] 149-62 (1955).

${ }^{10}$ J. Baker-Jarvis, R. G. Geyer, J. H. Grosvenor, M. D. Janezic, C. A. Jones, B Riddle, and C. M. Weil, "Dielectric Characterization of Low-Loss Materials-A Comparison of Techniques," IEEE Trans. Dielectr. Electr. Insul., 5 [4] 571-7 (1998)

${ }^{11}$ P. D. Domich, J. Baker-Jarvis, and R. G. Geyer, "Optimization Techniques for Permittivity and Permeability Determination," J. Res. Nat. Inst. Stand., 96 [5] 565-75 (1991). 